\title{
Substituição do milho pela casca de café ou de soja em dietas para vacas leiteiras: comportamento ingestivo, concentração de nitrogênio uréico no plasma e no leite, balanço de compostos nitrogenados e produção de proteína microbiana ${ }^{1}$
}

\author{
André Soares de Oliveira ${ }^{2}$, José Maurício de Souza Campos ${ }^{3}$, Sebastião de Campos \\ Valadares Filho ${ }^{3}$, Anderson Jorge de Assis ${ }^{4}$, Rafael Monteiro Araújo Teixeira ${ }^{5}$, Luciana \\ Navajas Rennó 6 , Douglas dos Santos Pina ${ }^{5}$, Gustavo Soares de Oliveira ${ }^{7}$
}

\author{
${ }^{1}$ Projeto financiado parcialmente pela Fundação de Amparo à Pesquisa do Estado de Minas Gerais - FAPEMIG. \\ 2 Doutorando do DZO/UFV. Bolsista do CNPq. \\ ${ }^{3}$ Departamento de Zootecnia/UFV. \\ ${ }^{4}$ Doutor em Zootecnia (Nutrição e Produção de Ruminantes) pela UFV. \\ ${ }^{5}$ Doutorando do DZO/UFV. \\ 6 UNIPAC, Juiz de Fora - MG. \\ 7 Graduando em Zootecnia/UFV.
}

RESUMO - Objetivou-se avaliar o efeito da substituição do milho pela casca de café ou pela casca de soja em dietas à base de cana-de-açúcar, com $60 \%$ de concentrado, sobre o comportamento ingestivo, o pH e a concentração de amônia no líquido ruminal, a excreção de uréia na urina (EU), a concentração de N-uréia no plasma (NUP) e no leite (NUL), o balanço de compostos nitrogenados e a síntese de proteína microbiana em vacas leiteiras, em comparação a uma dieta com silagem de milho. Foram utilizadas 12 vacas holandesas, puras e mestiças, distribuídas em três quadrados latinos 4 x 4 . A dieta controle foi composta de silagem de milho e $40 \%$ de concentrado (SiMi), com base na MS. Foram utilizadas três dietas contendo cana-de-açúcar e $60 \%$ de concentrado, de modo que os percentuais de substituição do milho foram $0 \%$ (CMi), $25 \%$ com casca de café (CCC) ou $50 \%$ com casca de soja (CCS), com base na MS total da dieta. O tempo total de mastigação foi menor para a dieta SiMi e não foi afetado pela inclusão de casca de café ou casca de soja. $\mathrm{O}$ pH ruminal não diferiu nos tempos 0 e 3 horas após a alimentação matinal. A dieta CCC resultou, três horas após alimentação, em menor concentração de amônia ruminal em relação às demais, com exceção da dieta CMi. Não foram observadas diferenças na EU e NUL, sendo registrados valores médios de 179,31 mg/kg de PV e $12,59 \mathrm{mg} / \mathrm{dL}$, respectivamente. A substituição do milho pela casca de café ou de soja não promove melhora no ambiente ruminal. A síntese de compostos nitrogenados microbianos e a eficiência microbiana ruminal não são influenciadas pelas dietas e apresentam valores médios de $273 \mathrm{~g} / \mathrm{dia}$ e 130,08 gPBmic/kg de NDT, respectivamente.

Palavras-chave: eficiência do nitrogênio, funcionamento ruminal, subprodutos

\section{Replacing corn with coffee hulls or soyhulls in diets of dairy cows: chewing activity, ruminal metabolism, nitrogen utilization and microbial protein synthesis}

\footnotetext{
ABSTRACT - Twelve purebred and crossbred Holstein cows were assigned to three replicated $4 \times 4$ Latin squares to evaluate the effects of replacing corn grain with coffee hulls or soyhulls on chewing activity, ruminal metabolism, nitrogen utilization, and microbial protein synthesis. Animals were fed a control diet containing $60 \%$ corn silage and $40 \%$ concentrate (CS diet) or three sugarcane based diets with forage to concentrate ratio of 40:60. The sugarcane diets contained $100 \%$ of corn in the concentrate (SC diet) or partial replacement of corn with $25 \%$ of coffee hulls (SCH diet) or $50 \%$ of soyhulls (SSH diet). Total chewing time was lowest on CS and did not change by the inclusion of coffee hulls or soyhulls in the diet. Ruminal $\mathrm{pH}$ did not differ significantly at zero (pre-feeding) and at three hours after the morning feeding across diets. The same was observed for the ruminal concentration of ammonia $\mathrm{N}$ immediately before feeding. However, the concentration of ruminal ammonia $\mathrm{N}$ at three hours after feeding was lower on SCH than on CS and SSH diets but was similar to that of SC diet. No significant differences were observed for the urinary excretion of urea $\mathrm{N}$ and milk urea $\mathrm{N}$, which averaged $179.31 \mathrm{mg} / \mathrm{kg} \mathrm{BW}$ and $12.59 \mathrm{mg} / \mathrm{dL}$, respectively, among diets. Replacing corn grain with coffee hulls or soyhulls did not improve the ruminal environment. Microbial protein synthesis and microbial efficiency were both not affected by diets averaging 273 g/day and $130.08 \mathrm{~g}$ microbial $\mathrm{CP} / \mathrm{kg} \mathrm{TDN}$, respectively.
}

Key Words: nitrogen utilization, ruminal metabolism, feed by-products 


\section{Introdução}

A utilização de cana-de-açúcar para vacas de maior potencial de produção tem como consequiência a necessidade de inclusão de quantidades mais elevadas de concentrado na dieta (Costa et al., 2005), o que pode reduzir o $\mathrm{pH}$ ruminal e comprometer o funcionamento normal do rúmen. A substituição de grãos ricos em carboidratos rapidamente fermentáveis por fontes de carboidratos estruturais de alta digestibilidade, como a casca de soja, pode prevenir distúrbios no funcionamento ruminal (Ipharraguerre \& Clark, 2003).

Além disso, o fornecimento de altos níveis de concentrado pode prejudicar a sustentabilidade econômica do sistema de produção, gerando a necessidade de utilização de subprodutos da agroindústria, como casca de café ou de soja. A elevada disponibilidade e os preços competitivos da casca de café estimularam o desenvolvimento de pesquisas com 10 a 15\% de sua inclusão, com base na MS, em substituição parcial ao milho em dietas para vacas em lactação (Barcelos et al., 1995; Souza et al., 2005; Rocha et al., 2004).

No entanto, o valor energético desse subproduto está aquém ao do milho. Além disso, esse alimento contém alta proporção de compostos nitrogenados ligados à FDA e alto conteúdo de polifenóis totais (Barcelos et al., 2001; Valadares Filho et al., 2002) e, portanto, sua utilização pode afetar o crescimento dos microrganismos ruminais.

Os ruminantes dependem dos microrganismos ruminais para atender suas exigências de proteína e energia (Coelho da Silva \& Leão, 1979; Valadares Filho \& Valadares, 2001). Assim, a busca pela eficácia e eficiência nos sistemas de alimentação requer a otimização do crescimento microbiano com minimização de perdas potenciais de nutrientes.

Os microrganismos ruminais necessitam de condições específicas que permitam a normalidade do metabolismo e do crescimento. $\mathrm{O} \mathrm{pH}$ ruminal afeta o crescimento microbiano e deve se manter na faixa de $6,7 \pm 0,5$ para a adequada atividade microbiana (Van Soest, 1994). O tamponamento ruminal é mantido em condições normais principalmente por meio da saliva e remoção dos ácidos graxos voláteis por absorção.

A salivação é altamente relacionada à atividade mastigatória (mastigação e ruminação). Desse modo, a avaliação do comportamento alimentar, constituído pelos tempos de alimentação, ruminação e ócio e pelas eficiências de alimentação e ruminação, pode auxiliar nas avaliações de dietas e possibilitar o ajuste do manejo alimentar para melhora do desempenho produtivo (Dado \& Allen, 1995).

O crescimento microbiano é afetado pela disponibilidade de nutrientes exigidos pelos microrganismos ruminais, como carboidratos, amônia, peptídeos, aminoácidos, enxofre e ácidos graxos de cadeia ramificada (Van Soest, 1994).

A concentração de amônia ruminal tem sido utilizada como indicador da degradação protéica e da eficiência de utilização do nitrogênio da dieta e de crescimento microbiano. Alguns pesquisadores sugeriram limites inferiores de concentração de amônia ruminal para maximizar o crescimento microbiano (Satter \& Slyter, 1974; Leng \& Nolan, 1984). No entanto, a exigência de amônia ruminal para síntese microbiana não é homogênea entre os microrganismos e depende do substrato utilizado (Russell et al., 1992). Desse modo, torna-se necessário determinar ou estimar a produção de proteína microbiana, pois a concentração de amônia ruminal representa uma medida de excesso e não necessariamente reflete a eficiência de crescimento de todos os microrganismos ruminais (Morrison \& Mackie, 1996).

Entre os diferentes métodos para estimar a síntese de proteína microbiana, o uso de derivados de purina (DP) tem sido preferido pela simplicidade e por não utilizar animais fistulados (Valadares Filho \& Valadares, 2001; Rennó et al., 2000).

A uréia constitui a principal forma de excreção de compostos nitrogenados em mamíferos. Quando a taxa de síntese da amônia excede a taxa de utilização pelos microrganismos, observa-se elevação da concentração de amônia no rúmen, que é absorvida pela corrente sangüínea através da parede ruminal, sendo transportada até o fígado para ser detoxicada pela conversão a uréia (Frosi \& Mullbach, 1999). Como a uréia é uma pequena molécula solúvel em água e altamente permeável, está presente em todos os fluidos corporais, inclusive o sangue e o leite. Assim, a concentração de nitrogênio uréico no plasma (NUP) e/ou no leite (NUL) pode ser utilizada para monitorar a utilização do nitrogênio da dieta no sentido de evitar perdas econômicas, produtivas, reprodutivas e ambientais (Broderick \& Clayton, 1997).

Este trabalho foi realizado com o objetivo de avaliar o efeito da substituição do milho pela casca de café ou de soja em dietas à base de cana-de-açúcar, com $60 \%$ de concentrado, sobre o comportamento ingestivo, o pH e a concentração de amônia no rúmen, a excreção de uréia na urina, a concentração de uréia no plasma e no leite, o balanço de compostos nitrogenados e a síntese de proteína microbiana.

\section{Material e Métodos}

O experimento foi conduzido na Unidade de Ensino, Pesquisa e Extensão em Gado de Leite (UEPE-GL) do Departamento de Zootecnia (DZO) da Universidade Federal 
de Viçosa (UFV), em Viçosa-MG, durante o período de junho a setembro de 2003.

Foram utilizadas 12 vacas holandesas, puras e mestiças, distribuídas em três quadrados latinos $4 \times 4$, balanceados de acordo com o período de lactação. O experimento foi constituído de quatro períodos de 19 dias (os 12 primeiros de adaptação às dietas e os demais para coleta de amostras).

Os animais foram alimentados com quatro dietas. A dieta controle (SiMi) foi constituída de silagem de milho (Zea mays, híbrido AG-1051) com 40\% de concentrado, com base na MS, e as dietas à base de cana-de-açúcar (Saccharum officinarum, L; variedade RB 73-9735) foram compostas de $60 \%$ de concentrado, com base na MS, de modo que os percentuais de substituição do milho foram $0 \%$ (CMi), $25 \%$ com casca de café (CCC) ou 50\% com casca de soja (CCS), com base na MS total da dieta. Às dietas à base de cana-deaçúcar, adicionou-se $1 \%$ da mistura de nove partes de uréia e uma parte de sulfato de amônio, com base na matéria natural, e, aos concentrados foram misturados bicarbonato de sódio e óxido de magnésio na proporção de 2:1 (Tabela 1). As dietas foram formuladas para serem isonitrogenadas, com $14 \%$ de $\mathrm{PB}$, de modo a atender às exigências nutricionais de uma vaca com $580 \mathrm{~kg}$ de peso corporal produzindo $20 \mathrm{~kg} /$ dia de leite com $3,5 \%$ de gordura (NRC, 2001). Os procedimentos de preparo e análise das amostras de alimentos e sobras e a composição químico-bromatológica das dietas (Tabela 2) experimentais foram descritos por Oliveira et al. (2007).

No 170 dia de cada período experimental, os animais foram submetidos à observação visual para avaliação do comportamento ingestivo. Os animais foram observados a cada dez minutos, durante 24 horas, para determinação do tempo despendido em alimentação, ruminação e ócio. No dia seguinte, foi realizada a contagem do número de mastigações merícicas e do tempo despendido na ruminação de cada bolo ruminal com a utilização de cronômetro digital. Para essa avaliação, foram feitas observações de três bolos ruminais em três períodos diferentes do dia (10-12h; 14-16h e 19-21h), calculando-se a média do número de mastigações merícicas e o tempo gasto por bolo ruminal. Essa observação foi feita em todos os animais do experimento. Durante a observação noturna, o ambiente foi mantido com iluminação artificial.

As eficiências de alimentação (EAL) e ruminação (ERU), o número de bolos ruminais por dia (NBR), o tempo de mastigação total por dia (TMT) e o número de mastigações merícicas por dia $\left(\mathrm{NMM}_{\mathrm{nd}}\right)$ foram obtidos segundo metodologia descrita por Büger et al. (2000).

O líquido ruminal foi coletado utilizando-se sonda esofágica, segundo Ortolani (1981), para determinação do

Tabela 1 - Composição percentual dos ingredientes nas dietas, expressa na MS

Table 1 - Ingredient composition (\%) of the diet (DM basis)

\begin{tabular}{|c|c|c|c|c|}
\hline & \multicolumn{4}{|c|}{$\begin{array}{c}\text { Dieta } \\
\text { Diet }\end{array}$} \\
\hline & \multirow[t]{3}{*}{$\begin{array}{l}\mathrm{SiMi} \\
C S\end{array}$} & \multicolumn{3}{|c|}{$\begin{array}{c}\text { Cana-de-açúcar }+1 \% \text { uréia/SA } \\
\text { Sugarcane }+1 \% \text { urea/AS }\end{array}$} \\
\hline & & $\mathrm{Cmi}$ & $\mathrm{CCC}$ & $\mathrm{CCS}$ \\
\hline & & $S C$ & $\mathrm{SCH}$ & SSH \\
\hline Silagem de milho (Corn silage) & 60,00 & & & \\
\hline Cana-de-açúcar ${ }^{1}$ (Sugarcane) & & 40,00 & 40,00 & 40,00 \\
\hline Fubá de milho (Ground corn) & 21,00 & 41,09 & 31,09 & 21,09 \\
\hline Casca de café (Coffee hulls) & & & 10,00 & \\
\hline Casca de soja (Soyhulls) & & & & 20,00 \\
\hline Farelo de soja (Soybean meal) & 8,50 & 6,90 & 6,60 & 3,90 \\
\hline Farelo de trigo (Wheat bran) & 6,54 & 6,29 & 6,66 & 9,56 \\
\hline Farelo de algodão (Cottonseed meal) & 2,03 & 3,10 & 3,10 & 3,10 \\
\hline Uréia/SA (9:1) (Urea/AS, 9:1) & 0,60 & & & \\
\hline Tamponantes $^{2}$ (Buffers) & & 0,85 & 0,85 & 0,85 \\
\hline Mistura mineral $^{3}$ (Mineral mix) & 1,33 & 1,77 & 1,70 & 1,50 \\
\hline Total & 100,00 & 100,00 & 100,00 & 100,00 \\
\hline \multicolumn{5}{|c|}{ 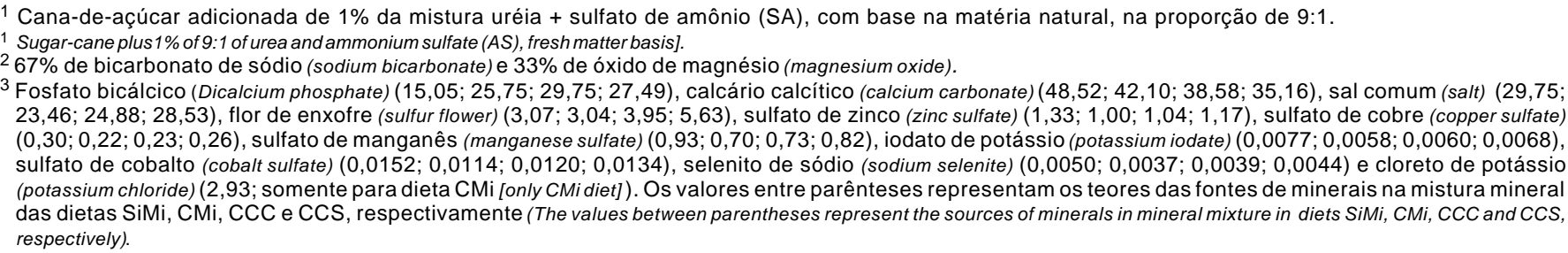 } \\
\hline
\end{tabular}


Tabela 2 - Teores médios dos nutrientes obtidos nas dietas experimentais

Table 2 - Average contents of nutrients in the experimental diets

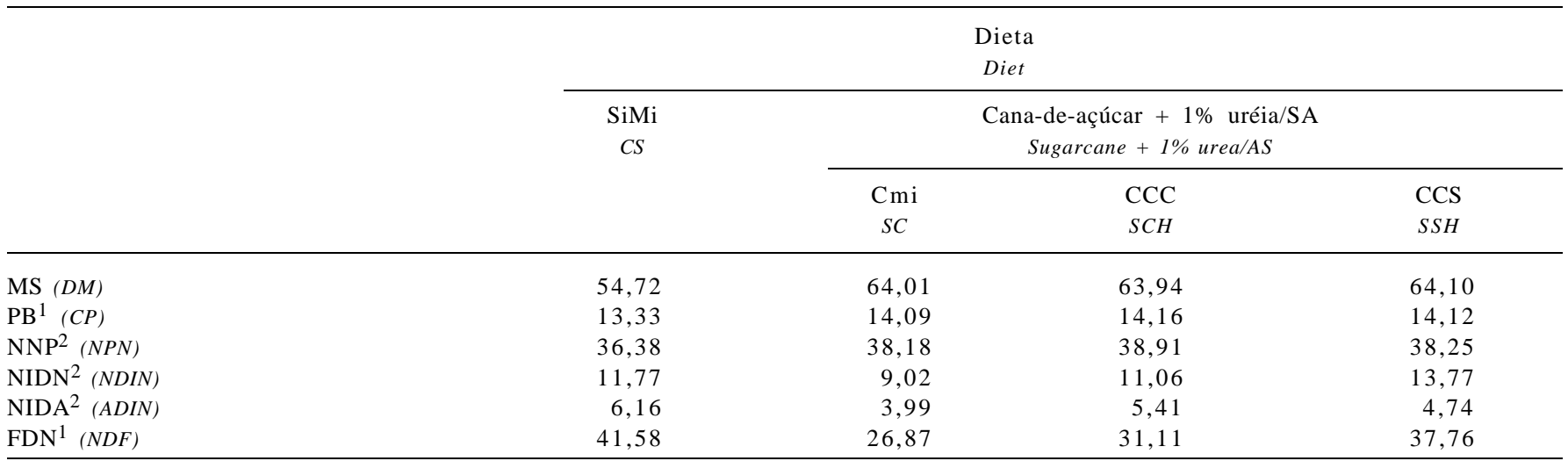

1 Porcentagem da MS (\% DM).

2 Porcentagem do nitrogênio total (\% of total $N$ ).

pH e da concentração dos compostos nitrogenados amonicais $\left(\mathrm{N}-\mathrm{NH}_{3}\right)$, nos tempos 0 (zero), antes da alimentação, e 3 horas após a alimentação matinal do 19으 dia de cada período experimental.

As amostras de leite foram coletadas no 16으 dia de cada período experimental, nas ordenhas da manhã e da tarde, para as análises de compostos nitrogenados totais, alantoína e uréia. Os procedimentos para análise dos compostos nitrogenados totais do leite foram descritos por Oliveira et al. (2007). Parte da amostra composta de leite foi desproteinizada com ácido tricloroacético a $25 \%$, filtrada em papel-filtro e armazenada a $-15^{\circ} \mathrm{C}$ para análises de uréia e alantoína no filtrado.

Amostras spot de urina foram obtidas de todas as vacas no 16 을 dia de cada período experimental, 4 horas após a alimentação matinal, durante micção estimulada por massagem na vulva. A urina foi filtrada e alíquotas de $10 \mathrm{~mL}$ foram retiradas e diluídas imediatamente em $40 \mathrm{~mL}$ de ácido sulfúrico a 0,036 N para evitar destruição bacteriana dos derivados de purinas e precipitação do ácido úrico. Em seguida, as alíquotas foram armazenadas a $-15^{\circ} \mathrm{C}$ para análises de nitrogênio total, uréia, alantoína, ácido úrico e creatinina.

O balanço de compostos nitrogenados $(\mathrm{BN})$ foi obtido pela diferença entre o total de nitrogênio ingerido (N-total) e o total de nitrogênio excretado nas fezes ( $\mathrm{N}$-fezes), na urina (N-urina) e no leite (N-leite). A determinação do nitrogênio total nas fezes e na urina foi feita segundo metodologia descrita por Silva \& Queiroz (2002).

Foram coletadas amostras de sangue de todas as vacas no 16ํㅡ dia de cada período experimental, 4 horas após a alimentação matinal, utilizando-se EDTA como anticoagulante. Logo após a coleta, as amostras foram centrifugadas (2.236 $\mathrm{x} g$ por 15 minutos) e o plasma sangüíneo foi acondicionado em recipientes de vidro e congelado a $-15^{\circ} \mathrm{C}$ para posteriores análises das concentrações de uréia.

As análises de alantoína na urina e no leite foram feitas pelo método colorimétrico, segundo Fujihara et al. (1987), descrito por Chen \& Gomes (1992). As determinações de creatinina, ácido úrico e uréia foram realizadas utilizando-se kits comerciais (Labtest).

O volume urinário total diário foi estimado dividindo-se as excreções urinárias diárias de creatinina pelos valores da concentração de creatinina na urina, segundo Valadares Filho \& Valadares (2001), a partir da proposição de 24,05 $\mathrm{mg} / \mathrm{kg}$ de PV de creatinina (Chizzotti, 2004).

A excreção total de DP foi calculada pela soma das quantidades de alantoína e ácido úrico excretados na urina e da quantidade de alantoína excretada no leite, expressas em $\mathrm{mmol} / \mathrm{dia}$.

As purinas absorvidas (X, mmol/dia) foram calculadas a partir da excreção de DP (Y, mmol/dia), por meio da equação $\mathrm{Y}=0,85 \mathrm{X}+0,385 \mathrm{PV}^{0,75}$, em que 0,85 é a recuperação de purinas absorvidas como derivados de purinas e 0,385 $\mathrm{PV}^{0,75}$, a contribuição endógena para excreção de purinas (Verbic et al., 1990).

A síntese de compostos nitrogenados microbianos no rúmen (Y, $\mathrm{g}$ N/dia) foi calculada em função das purinas absorvidas (X, mmol/dia), por meio da equação $\mathrm{Y}=(70 \mathrm{X}) /(0,83 \times 0,116 \times 1000)$, em que 70 representa o conteúdo de $\mathrm{N}$ nas purinas ( $\mathrm{mg} \mathrm{N} / \mathrm{mmol}$ ); 0,83, a digestibilidade das purinas microbianas e 0,116 , a relação $\mathrm{N}$-purina: $\mathrm{N}$ total nas bactérias (Chen \& Gomes, 1992).

Os dados obtidos foram submetidos à análise de variância e ao teste de média (Tukey), a 5\% de significância, utilizando-se o programa SAEG, versão 7.0 (UFV, 1997). 
Tabela 3 - Médias e coeficientes de variação (CV) para os tempos despendidos (horas/dia) com alimentação, ruminação e ócio entre as dietas experimentais

Table 3 - Means and coefficients of variation (CV) for time spent (hours/day) feeding, ruminating and idle on the different diets

\begin{tabular}{|c|c|c|c|c|c|}
\hline & & & $\begin{array}{r}\text { Die } \\
\text { Dic }\end{array}$ & & \\
\hline & $\begin{array}{c}\mathrm{SiMi} \\
C S\end{array}$ & & $\begin{array}{l}\text { úcar }+ \\
\text { ine }+1 \%\end{array}$ & & $\mathrm{CV}(\%)$ \\
\hline & & $\begin{array}{c}\mathrm{Cmi} \\
S C\end{array}$ & $\begin{array}{l}\mathrm{CCC} \\
\mathrm{SCH}\end{array}$ & $\begin{array}{l}\mathrm{CCS} \\
\mathrm{SSH}\end{array}$ & \\
\hline Alimentação (Feeding) & $5,1 \mathrm{a}$ & $4,1 \mathrm{~b}$ & $4,6 \mathrm{~b}$ & $4,2 b$ & 12,98 \\
\hline Ruminação (Ruminating) & $9,1 \mathrm{a}$ & $7,3 \mathrm{~b}$ & $7,4 b$ & $7,3 \mathrm{~b}$ & 12,72 \\
\hline Ócio (Idle) & $9,9 \mathrm{~b}$ & $12,7 \mathrm{a}$ & $12,0 \mathrm{a}$ & $12,5 \mathrm{a}$ & 9,89 \\
\hline
\end{tabular}

Médias seguidas de mesma letra na linha não diferem $(P>0,05)$ pelo teste Tukey.

Means followed by same letters in a row do not differ $(P>0.05)$ by Tukey test.

Tabela 4 - Médias e coeficientes de variação (CV) dos consumos de matéria seca (CMS) e de fibra em detergente neutro (CFDN), eficiência de alimentação de MS (EAL) e de FDN (EAL FDN), eficiência de ruminação da MS (ERU) e da FDN (ERU $\mathrm{FDN})$, tempo de mastigação total (TMT), número de bolos ruminais (NBR), de mastigações merícicas $\left(\mathrm{NMM}_{\mathrm{nd}}\right)$ e de mastigações merícicas por bolo ruminal $\left(\mathrm{NMM}_{\mathrm{nb}}\right)$ e tempo de ruminação por bolo ruminal (TRB) obtidos com as dietas experimentais

Table 4 - Means and coefficients of variation (CV) for intakes of DM (DMI) and ND (NDFI), feed DM efficiency (FEF) and feed NDF efficiency (FEFNDF), DM rumination efficiency (RUE) and NDF rumination efficiency (RUENDF), total chewing time (TCT), number of ruminal bolus (NRB), number of rumination chews (NRCnd), number of rumination chews per bolus (NRCnb) and rumination time per bolus (RTB) on the different diets

\begin{tabular}{|c|c|c|c|c|c|}
\hline & \multicolumn{5}{|c|}{$\begin{array}{l}\text { Dieta } \\
\text { Diet }\end{array}$} \\
\hline & \multirow[t]{2}{*}{$\begin{array}{l}\mathrm{SiMi} \\
\text { CS }\end{array}$} & \multicolumn{3}{|c|}{$\begin{array}{c}\text { Cana-de-açúcar }+1 \% \text { uréia/SA } \\
\text { Sugarcane }+1 \% \text { urea/AS }\end{array}$} & \multirow[t]{2}{*}{$\mathrm{CV}(\%)$} \\
\hline & & $\begin{array}{c}\mathrm{Cmi} \\
S C\end{array}$ & $\begin{array}{l}\mathrm{CCC} \\
\mathrm{SCH}\end{array}$ & $\begin{array}{l}\text { CCS } \\
\text { SSH }\end{array}$ & \\
\hline CMS $(\mathrm{kg} / \mathrm{dia})(I D M, \mathrm{~kg} /$ day $)$ & 18,3 & 20,07 & 18,83 & 20,29 & 10,45 \\
\hline CFDN (kg/dia) (INDF, kg/day) & $7,2 \mathrm{a}$ & $5,0 \mathrm{~b}$ & $5,4 \mathrm{~b}$ & $7,26 \mathrm{a}$ & 16,39 \\
\hline EAL $(\mathrm{gMS} / \mathrm{h})(F E F, g D M / h)$ & $3.722,6 \mathrm{~b}$ & $5.082,6 \mathrm{a}$ & $4.135,8 \mathrm{~b}$ & $5.021,9 \mathrm{a}$ & 15,18 \\
\hline $\mathrm{EAL}_{\mathrm{FDN}}(\mathrm{gFDN} / \mathrm{h})(F E F N D F, g N D F / h)$ & $1.452,3 b$ & $1.268,1 \mathrm{~b}$ & $1.169,7 \mathrm{~b}$ & $1.800,1 \mathrm{a}$ & 19,59 \\
\hline ERU $(\mathrm{gMS} / \mathrm{h})(R U E, g D M / h)$ & $2.058,6 \mathrm{~b}$ & $2.911,6 \mathrm{a}$ & $2.601,3 \mathrm{a}$ & $2.815,7 \mathrm{a}$ & 16,56 \\
\hline $\mathrm{ERU}_{\mathrm{FDN}}(\mathrm{gFDN} / \mathrm{h})(R U E N D F, g N D F / h)$ & $804,0 \mathrm{~b}$ & $735,1 \mathrm{~b}$ & $741,2 \mathrm{~b}$ & $1.007,1 \mathrm{a}$ & 19,27 \\
\hline TMT (h/dia) $(T C T$, h/day $)$ & $14,1 \mathrm{a}$ & $11,3 \mathrm{~b}$ & $12,0 \mathrm{~b}$ & $11,5 \mathrm{~b}$ & 9,52 \\
\hline NBR $\left(\mathrm{n}^{\mathrm{O}} / \mathrm{dia}\right)(N R B, n . /$ day $)$ & $621,3 \mathrm{a}$ & $472,2 \mathrm{~b}$ & $503,4 \mathrm{~b}$ & $462,7 \mathrm{~b}$ & 17,91 \\
\hline $\mathrm{NMM}_{\mathrm{nd}}\left(\mathrm{n}^{\circ} / \mathrm{dia}\right)($ NRCnd, n./day) & $35.548 \mathrm{a}$ & $26.152 b$ & $27.811 \mathrm{~b}$ & $26.676 \mathrm{~b}$ & 16,01 \\
\hline $\mathrm{NMM}_{\mathrm{nb}}\left(\mathrm{n}^{\mathrm{O}} /\right.$ bolo $)$ (NRCnb, n./bolus $)$ & 57,9 & 57,6 & 55,5 & 59,3 & 11,31 \\
\hline TRB (seg/bolo) (RTB, sec/bolus) & 53,2 & 57,6 & 53,8 & 59,2 & 10,87 \\
\hline
\end{tabular}

Médias seguidas de mesma letra na linha não diferem $(P>0,05)$ pelo teste Tukey.

Means followed by same letters in a row do not different $(P>0.05)$ by Tukey test.

\section{Resultados e Discussão}

Os tempos médios despendidos em alimentação e ruminação para a dieta com silagem de milho (SiMi) foram maiores $(\mathrm{P}<0,05)$ que os obtidos com as dietas à base de cana-de-açúcar, que não diferiram $(\mathrm{P}>0,05)$ significativamente (Tabela 3). Contrariamente, quando alimentados com a dieta à base de silagem de milho, os animais mantiveram-se por menos $(\mathrm{P}<0,05)$ tempo em ócio.

Os tempos gastos com alimentação e ruminação apresentaram correlação positiva com o teor e consumo de FDN (Dado \& Allen, 1995). Assim, os menores $(\mathrm{P}<0,05)$ tempos observados com alimentação e ruminação para as dietas à base de cana-de-açúcar sem casca (CMi) e com $25 \%$ de substituição do milho por casca de café (CCC), em relação à dieta com silagem de milho (SiMi), podem estar relacionados aos menores teores e consumos de FDN.

Entretanto, a mesma explicação não é válida para a dieta à base de cana-de-açúcar com 50\% de susbtituição do milho por casca de soja (CCS), pois, embora o consumo de FDN desta dieta não tenha diferido $(\mathrm{P}>0,05)$ em relação à dieta $\mathrm{SiMi}$, os tempos em alimentação e ruminação foram menores $(\mathrm{P}<0,05)$ (Tabela 4). Fatores intrínsecos à casca de soja, como a rápida taxa de digestão da parede celular e pequeno 
tamanho de partícula com alta capacidade de hidratação (Ipharraguerre \& Clark, 2003), podem ter reduzido os tempos totais para ingestão de MS e ruminação do bolo alimentar.

$\mathrm{Na}$ Tabela 4 constam as médias e os coeficientes de variação obtidos para as características do comportamento ingestivo dos animais alimentados com as diferentes dietas experimentais.

As dietas SiMi e CCC não diferiram $(\mathrm{P}>0,05)$ quanto à eficiência de alimentação da MS, todavia, a EAL foi maior $(\mathrm{P}<0,05)$ para as dietas $\mathrm{CMi}$ e CCS, que não diferiram $(\mathrm{P}>0,05)$ entre si. Como o consumo de MS não foi influenciado $(\mathrm{P}>0,05)$ pelas dietas, a menor $(\mathrm{P}<0,05)$ eficiência para dieta SiMi foi atribuída ao maior tempo gasto com alimentação. O maior teor de umidade da dieta SiMi alterou o comportamento alimentar dos animais, que aumentaram o tempo de alimentação para compensar o menor teor de MS por bocado.

$\mathrm{O}$ tempo gasto em alimentação não diferiu $(\mathrm{P}>0,05)$ entre os animais alimentados com as dietas $\mathrm{CCC}$ e $\mathrm{CMi}$, mas apresentou tendência de aumento, o que explica o menor consumo de MS por unidade de tempo.

A eficiência de alimentação da FDN foi maior $(\mathrm{P}<0,05)$ para a dieta CCS, enquanto as demais não diferiram $(\mathrm{P}>0,05)$ entre si. O maior consumo de FDN no mesmo tempo de ruminação explica as diferenças da dieta CCS em relação àquelas à base de cana-de-açúcar. O menor tempo de ruminação da dieta CCS, com mesmo consumo de FDN, explica a maior eficiência de alimentação da FDN da dieta SiMi.

A eficiência de ruminação da MS foi menor $(\mathrm{P}<0,05)$ para a dieta $\mathrm{SiMi}$, enquanto as dietas $\mathrm{CMi}$ não diferiram $(\mathrm{P}>0,05)$. O maior $(\mathrm{P}<0,05)$ tempo gasto com ruminação, mas com o mesmo consumo em relação às demais dietas, explica a menor quantidade de MS ingerida da dieta SiMi por unidade de tempo.

A dieta CCS promoveu maior eficiência de ruminação da FDN $(\mathrm{P}<0,05)$, não sendo observadas diferenças entre as demais. As caraterísticas favoráveis da parede celular da casca de soja permitiram maior consumo de FDN e mesmo tempo de ruminação em comparação às demais dietas.

O tempo total de mastigação, o número de bolos ruminais e o número de mastigações merícicas foram maiores $(\mathrm{P}<0,05)$ para a dieta $\mathrm{SiMi}$, enquanto aquelas à base de cana-deaçúcar não diferiram $(\mathrm{P}>0,05)$ quanto a essas variáveis, que se correlacionaram positivamente com os tempos gastos em alimentação e ruminação (Dado \& Allen, 1995). Os resultados observados para a dieta SiMi podem estar relacionados aos maiores tempos gastos com alimentação e ruminação em comparação às dietas à base de cana-de-açúcar.
Tabela 5 - Médias e coeficientes de variação $(\mathrm{CV})$ para $\circ \mathrm{pH}$ e a concentração de $\mathrm{N}-\mathrm{NH}_{3}$ do líquido ruminal nos tempos 0 e 3 horas após a alimentação

Table 5 - Means and coefficients of variation (CV) for ruminal $\mathrm{pH}$ and ruminal concentration of $\mathrm{NH}_{3}-\mathrm{N}$ at zero (pre-feeding) and at three hours after feeding

\begin{tabular}{|c|c|c|c|c|c|}
\hline Tempo & SiMi & $\mathrm{CMi}$ & $\mathrm{CCC}$ & CCS & CV (\%) \\
\hline \multirow[t]{2}{*}{ Time } & $C S$ & $S C$ & $\mathrm{SCH}$ & $S S H$ & \\
\hline & \multicolumn{5}{|c|}{$\mathrm{pH}$} \\
\hline Hora 0 & 7,29 & 7,19 & 7,32 & 7,18 & 2,28 \\
\hline \multirow{4}{*}{$\begin{array}{l}\text { Hour } 0 \\
\text { Hora } 3 \\
\text { Hour } 3 \\
\end{array}$} & & & & & \\
\hline & 6,92 & 6,93 & 6,99 & 6,86 & 2,85 \\
\hline & & & & & \\
\hline & \multicolumn{5}{|c|}{$\mathrm{N}-\mathrm{NH}_{3}(\mathrm{mg} / \mathrm{dL})$} \\
\hline Hora 0 & 4,24 & 3,62 & 3,59 & 3,72 & 27,86 \\
\hline \multicolumn{6}{|l|}{ Hour 0} \\
\hline Hora 3 & $11,82 \mathrm{a}$ & $10,56 a b$ & $8,66 \mathrm{~b}$ & $12,09 \mathrm{a}$ & 24,36 \\
\hline Hour 3 & & & & & \\
\hline
\end{tabular}

Médias seguidas de mesma letra na linha não diferem $(P>0,05)$ pelo teste Tukey.

Means followed by same letters in a row do not differ $(P>0.05)$ by Tukey test.

O número de mastigações merícicas por bolo ruminal e o tempo de ruminação por bolo ruminal não foram influenciados $(\mathrm{P}>0,05)$ pelas dietas. $\mathrm{O}$ maior tempo $(\mathrm{P}<0,05)$ despendido com ruminação para a dieta SiMi se relacionou mais ao número diário de bolos ruminais necessários para a ruminação que ao número de mastigações merícicas e ao tempo de ruminação por unidade de bolo ruminal.

$\mathrm{Na}$ Tabela 5 constam os valores de $\mathrm{pH}$ e a concentração de amônia do líquido ruminal nos tempos 0 e 3 horas após a alimentação. Apesar do maior nível de concentrado (60\% da MS) nas dietas à base de cana-de-açúcar, o pH ruminal não diferiu $(\mathrm{P}>0,05)$ entre os tempos de coleta e manteve-se na faixa considerada ideal para máximo crescimento microbiano (Van Soest, 1994).

$\mathrm{O} \mathrm{pH}$ do líquido ruminal de animais consumindo dietas à base de cana-de-açúcar normalmente é alto e estável, variando de 6,8 a 7,3 como resultado da alta taxa de fluxo salivar decorrente do tempo considerável de mastigação dessas dietas (Leng \& Preston, 1976) e da ação regulatória dos protozoários sobre a disponibilidade de carboidratos solúveis (Minor et al., 1971, citados por Oliveira, 1999; Souza, 2003).

Contrariamente, foi observado menor tempo despendido com mastigação para as dietas à base de cana-de-açúcar em comparação àquela com silagem de milho. Contudo, esse menor tempo não foi suficiente para comprometer a secreção salivar e o tamponamento ruminal, provavelmente em virtude da maior taxa de absorção de ácidos graxos voláteis (AGV) das dietas com cana-de-açúcar, compensando a 
maior produção de $\mathrm{AGV}$, e dos efeitos tamponante do bicabornato de sódio e alcalinizante do óxido de magnésio e da amônia proveniente da uréia dietética.

A substituição de grãos de cereais ricos em carboidratos rapidamente fermentáveis por alimentos ricos em carboidratos estruturais de alta digestão, como a casca de soja, tem sido utilizada para prevenir distúrbios no funcionamento ruminal (Ipharraguerre \& Clark, 2003), pois a fermentação ruminal dos carboidratos estruturais não produz ácidos capazes de reduzir o pH ruminal (Hall, 2001). No entanto, não foi observada melhora no ambiente ruminal $(\mathrm{pH})$ com a substituição de 50\% do milho pela casca de soja na dieta à base de cana-de-açúcar, o que está de acordo com as observações de Cunningham et al. (1993) e Elliott et al. (1995). A ausência de diferenças nos tempos despendidos com mastigação, quando o milho foi substituído pela casca de soja, pode explicar o resultado obtido, pois o tempo de mastigação correlaciona-se positivamente à secreção de saliva e, conseqüentemente, ao tamponamento ruminal (Mertens, 2001).

No tempo zero não houve diferença $(\mathrm{P}>0,05)$ para a concentração de amônia ruminal. Entretanto, três horas após a alimentação, a dieta $\mathrm{CCC}$ promoveu menor $(\mathrm{P}<0,05)$ concentração de amônia ruminal em relação às dietas SiMi e CCS, não diferindo $(\mathrm{P}>0,05)$ da dieta $\mathrm{CMi}$. As elevadas concentrações de compostos nitrogenados presentes na fração fibrosa da casca de café na forma de NIDN e NIDA (Oliveira et al., 2007), considerados de baixa disponibilidade para os microrganismos do rúmen (Licitra et al., 1996), associadas ao maior teor de polifenóis totais (Orskov, 1992), podem ter sido a causa da menor degradabilidade ruminal da proteína da dieta e, conseqüentemente, da menor concentração de amônia ruminal.

As concentrações de amônia ruminal 3 horas após a alimentação, obtidas para todas as dietas, foram superiores ao mínimo de $5 \mathrm{mg} / \mathrm{dL}$ sugerido por Satter \& Slyter (1974) para o maximar o crescimento microbiano in vitro, mas inferiores ao mínimo de $15 \mathrm{mg} / \mathrm{dL}$ sugerido por Leng \& Nolan (1984). No entanto, a concentração ruminal representa uma medida de excesso e, necessariamente, não reflete a eficiência de crescimento de todos os microrganismos ruminais (Morrison \& Mackie, 1996). A exigência de amônia ruminal como fonte de nitrogênio para síntese microbiana não é homogênea, sendo de $100 \%$ do nitrogênio total para os microrganismos que degradam carboidratos fibrosos e de $34 \%$ para aqueles que degradam CNF (Russell et al., 1992). Como as dietas apresentaram elevado teor de CNF, os valores observados de amônia ruminal possivelmente não comprometeram o crescimento microbiano.

Os níveis de excreção de uréia pela urina (EU-urina), as concentrações de nitrogênio uréico no leite (NUL) e no plasma (NUP) e a relação NUL/NUP obtidos para as dietas são apresentados na Tabela 6 . Não foram observadas diferenças $(\mathrm{P}>0,05)$ para EU-urina, NUL e relação NUL/NUP entre as dietas experimentais. No entanto, o nível de NUP foi menor $(\mathrm{P}<0,05)$ na dieta SiMi em relação àquelas com cana-de-açúcar, à exceção da dieta CCC. Entre as dietas à base de cana-de-açúcar, a CCC apresentou menor $(\mathrm{P}<0,05)$ concentração de NUP em relação à $\mathrm{CMi}$, mas não diferiu $(\mathrm{P}>0,05)$ da dieta CCS.

A concentração de NUP correlaciona-se positivamente aos teores dietéticos de PB (Broderick \& Clayton, 1997; Jonker et al., 1998; Chizzotti, 2004; Nousiaine et al., 2004) e PDR (Oliveira et al., 2001; Chizzotti, 2004). Assim, o menor valor de NUP obtido para a dieta SiMi pode ser atribuído ao menor consumo de $\mathrm{PB}(2,54 \mathrm{~kg} / \mathrm{dia})$ em relação às dietas CMi $(2,81 \mathrm{~kg} / \mathrm{dia})$ e CCS $(2,86 \mathrm{~kg} / \mathrm{dia})$, como verificado por Oliveira et al. (2007). Embora o consumo de $\mathrm{PB}$ não tenha diferido $(\mathrm{P}>0,05)$ entre as dietas à base de cana-de-açúcar, o menor valor de NUP para a dieta CCC

Tabela 6 - Excreção urinária de uréia (EU-urina), concentrações de nitrogênio uréico no leite (NUL) e no plasma (NUP) e relação NUL/NUP obtidos para as dietas experimentais

Table 6 - Urinary excretion of urea N(UE-urine), milk urea nitrogen (MUN), plasma urea nitrogen (PUN), and MUN/PUN ratio observed on the different diets

\begin{tabular}{|c|c|c|c|c|c|}
\hline & \multicolumn{4}{|c|}{$\begin{array}{l}\text { Dieta } \\
\text { Diet }\end{array}$} & \multirow{3}{*}{$\mathrm{CV}(\%)$} \\
\hline & \multirow[t]{2}{*}{$\begin{array}{l}\mathrm{SiMi} \\
\text { CS }\end{array}$} & \multicolumn{3}{|c|}{$\begin{array}{c}\text { Cana-de-açúcar }+1 \% \text { uréia/SA } \\
\text { Sugarcane }+1 \% \text { urea/AS }\end{array}$} & \\
\hline & & $\begin{array}{c}\mathrm{Cmi} \\
S C\end{array}$ & $\begin{array}{l}\mathrm{CCC} \\
\mathrm{SCH}\end{array}$ & $\begin{array}{l}\text { CCS } \\
\text { SSH }\end{array}$ & \\
\hline EU-urina, $\mathrm{mg} / \mathrm{kg} \mathrm{PV}$ (UE-urine, $m g / k g B W$ ) & 172,7 & 181,5 & 182,3 & 180,7 & 47,31 \\
\hline $\mathrm{NUL}(M U N), \mathrm{mg} / \mathrm{dL}$ & 11,2 & 13,4 & 11,5 & 13,2 & 17,43 \\
\hline NUP $(P U N), \mathrm{mg} / \mathrm{dL}$ & $11,3 \mathrm{c}$ & $13,9 \mathrm{a}$ & $11,5 \mathrm{bc}$ & $13,7 \mathrm{ab}$ & 15,28 \\
\hline NUL/NUP (MUN/PUN) & 1,00 & 0,96 & 1,00 & 0,97 & 16,81 \\
\hline
\end{tabular}

Médias seguidas de mesma letra na linha não diferem $(P>0,05)$ pelo teste Tukey.

Means followed by same letters in a row do not differ $(P>0.05)$ by Tukey test. 
pode ter sido ocasionado pela menor degradabilidade ruminal da proteína.

A relação NUL/NUP média encontrada para as dietas $(0,98)$ reflete alta correlação en tre as duas variáveis observada em diversos trabalhos (Broderick \& Clayton, 1997; Jonker et al., 1998; Chizzotti, 2004). Broderick \& Clayton (1997), utilizando dados de 482 vacas holandesas, recomendaram a seguinte equação para estimar NUP a partir do NUL: $\mathrm{NUP}=1,021 \mathrm{NUL}+0,399\left(\mathrm{r}^{2}=0,918\right)$, que superestimou em apenas 5, 1, 6 e $2 \%$ o NUP observado nas dietas SiMi, CMi, CCC e CCS, respectivamente. Apesar da alta correlação e da mesma tendência de resultados, os valores de NUL não diferiram ( $\mathrm{P}>0,05)$ entre as dietas, ao contrário do NUP, o que pode ser explicado pelo maior coeficiente de variação $(\mathrm{CV})$ observado nos resultados de NUL em relação aos de NUP.

O valor médio observado para a concentração de NUL $(12,59 \mathrm{mg} / \mathrm{dL})$ está na faixa de balanceamento de energia e proteína considerada adequada, de 10 a $17 \mathrm{mg} / \mathrm{dL}$ (Broderick, 1995; Harris, 1996; Moore \& Varga, 1996; Jonker et al., 1998; Ferguson, 2001; Machado \& Cassoli, 2002) e abaixo do limite máximo de $19 \mathrm{mg} / \mathrm{dL}$ sugerido por Butler et al. (1995) a partir do qual ocorreria redução na eficiência reprodutiva.

Os valores médios e os coeficientes de variação para os consumos de compostos nitrogenados totais (NT), a excreção de compostos nitrogenados nas fezes (N-fecal), na urina (N-urina) e no leite (N-leite), o balanço de nitrogênio (BN) e as médias das excreções ou secreções em relação ao NT obtidas para as dietas são apresentados na Tabela 7.
A excreção de N-fecal, em g/dia e em \% do NT, da dieta $\mathrm{CCC}$ foi maior $(\mathrm{P}<0,05)$ que a da dieta $\mathrm{SiMi}$, que, por sua vez, não diferiu (P>0,05), em \% do NDT, das dietas CMi e CCS. Embora não tenham sido observadas diferenças $(\mathrm{P}>0,05)$ entre as dietas à base de cana-de-açúcar, os valores de $\mathrm{N}$-fecal para as dietas CCC e CCS foram numericamente maiores que os da dieta $\mathrm{CMi}$, provavelmente em razão da maior presença de compostos nitrogenados nas formas de NIDN e NIDA da casca de café e de NIDN da casca de soja em relação ao milho (Oliveira et al., 2007), de menor degradabilidade ruminal e digestão intestinal.

A excreção de N-urina, em g/dia e em \%do NT, não foi afetada $(\mathrm{P}>0,05)$ pelas dietas. Alguns trabalhos foram desenvolvidos para estimar a excreção de nitrogênio na urina a partir dos níveis de nitrogênio uréico no leite (NUL) como forma de monitorar o balanceamento protéico da dieta (Jonker et al., 1998; Chizzotti, 2004). Jonker et al. (1998) desenvolveram a equação: $\mathrm{N}$-urina $(\mathrm{g} / \mathrm{dia})=12,54 * \mathrm{NUL}$ (mg/dL), que superestimou em $29,7 \%$ o valor médio observado das dietas (121,75g/dia). Chizzotti (2004), por sua vez, propôs as equações: $\mathrm{N}$-urina $(\mathrm{g} / \mathrm{dia})=0,0135^{*} \mathrm{NUL}$ $(\mathrm{mg} / \mathrm{dL}) * \mathrm{PV}(\mathrm{kg})\left(\mathrm{r}^{2}=0,69\right)$ e $\mathrm{N}$-urina $(\mathrm{g} / \mathrm{dia})=$ $0,0151 * \mathrm{NUP}(\mathrm{mg} / \mathrm{dL}) * \mathrm{PV}(\mathrm{kg})\left(\mathrm{r}^{2}=0,69\right)$, que subestimaram em 18,6 e 9,0\% o valor médio observado de $\mathrm{N}$-urina.

A secreção de nitrogênio no leite (N-leite), expressa em $\mathrm{g} /$ dia, não diferiu $(\mathrm{P}>0,05)$ entre as dietas. Broderick \& Clayton (1997) desenvolveram uma equação que correlaciona a eficiência de utilização do nitrogênio aos teores de NUL: Eficiência de N (N-leite/NT) = -0,004NUL (mg/dL) + 0,309 $\left(r^{2}=0,626\right)$. Considerando o valor médio de NUL de

Tabela 7 - Consumos de compostos nitrogenados totais (NT), excreção de compostos nitrogenados nas fezes (N-fecal), na urina ( $\mathrm{N}$-urina) e no leite (N-leite), balanço de $\mathrm{N}(\mathrm{BN})$ e médias das excreções ou secreções em relação ao NT obtidas para as dietas experimentais

Table 7 - Intake of nitrogen (TN), excretion of nitrogen in feces (fecal $N$ ), urine (urinary N) and milk (milk N), Nbalance (NB), and proportion of nitrogen excreted in relation to $T N$ on the different diets

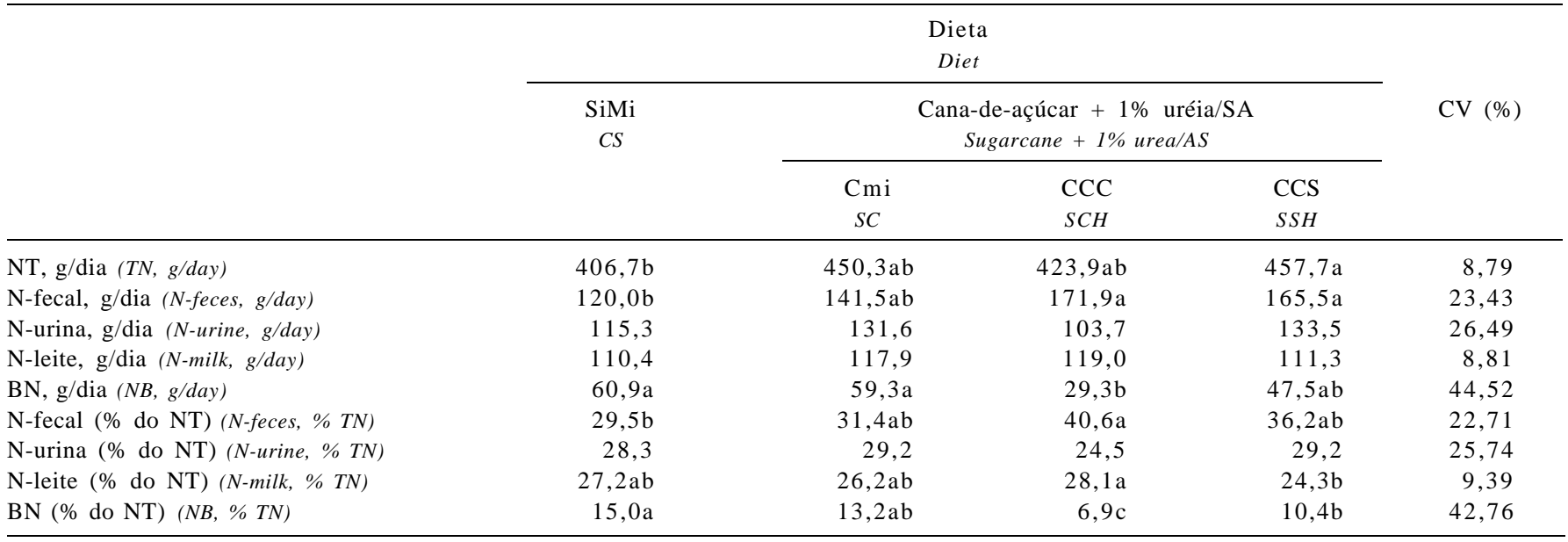

Médias seguidas de mesma letra na linha não diferem $(P>0,05)$ pelo teste Tukey.

Means followed by same letters in a row do not differ $(P>0.05)$ by Tukey test. 
Tabela 8 - Excreções de alantoína na urina (ALU) e no leite (ALL), concentrações de ácido úrico na urina (ACU), purinas totais (PT), purinas absorvidas (PA), síntese de compostos nitrogenados microbianos (Nmic) e eficiência microbiana (Emic) nos animais alimentados com as dietas experimentais

Table 8 - Urinary (AEU) and milk (AEM) excretion of allantoin, urinary excretion of uric acid (UUA), total purines (TP), absorbed purine (AP), microbial nitrogen synthesis (mic-N) and microbial efficiency (micE) on the different diets

\begin{tabular}{lrrr}
\hline & & & \multicolumn{2}{c}{ Dieta } \\
Diet
\end{tabular}

Médias seguidas de mesma letra na linha não diferem $(P>0,05)$ pelo teste Tukey.

Means followed by same letters in a row do not differ $(P>0.05)$ by Tukey test.

$12,59 \mathrm{mg} / \mathrm{dL}$ das dietas (Tabela 6), a equação subestimou em apenas $2,1 \%$ o valor médio observado de eficiência das dietas de $0,2643(26,43 \%$ de N-leite/N-total).

O balanço de nitrogênio $(\mathrm{BN})$ em $\mathrm{g} /$ dia foi menor $(\mathrm{P}<0,05)$ para a dieta CCC que para as demais, exceto CCS. As dietas CMi e CCS não diferiram $(\mathrm{P}>0,05)$ da dieta SiMi quanto ao $\mathrm{BN}$ em g/dia. O menor valor de BN para a dieta $\mathrm{CCC}$ pode ser atribuído ao maior valor de excreção de N-fecal. Mesmo assim, independentemente da dieta, não houve valor negativo para o $\mathrm{BN}$, indicando que o consumo de proteína atendeu às exigências protéicas das vacas.

Na Tabela 8 são apresentadas as excreções de alantoína na urina (ALU) e no leite (ALL), de ácido úrico na urina (ACU) e de purinas totais (PT) e absorvidas (PA), a síntese de compostos nitrogenados microbianos (Nmic) e a eficiência microbiana (Emic) obtidas para as dietas.

Nenhuma dessas variáveis foi influenciada $(\mathrm{P}>0,05)$ pelas dietas, o que está de acordo com as observações de Costa et al. (2005), que não encontrou diferenças na síntese de nitrogênio microbiano e na eficiência microbiana em vacas leiteiras com produção diária de $20 \mathrm{~kg}$ alimentadas com dietas à base de cana-de-açúcar com $60 \%$ de concentrado, em relação à dieta silagem de milho e $40 \%$ de concentrado. Os valores médios de Nmic e de Emic encontrados neste trabalho (273 g/dia e 130,08 g PBmic/kg de NDT) foram próximos aos observados por Costa et al. (2005), de 268,54 e 126,4 , respectivamente.

Avaliando os resultados obtidos, pode-se considerar que as dietas não diferiram quanto ao suprimento de energia, proteína e outros nutrientes essenciais para a síntese de proteína microbiana, principal fonte de aminoácidos para vacas em lactação (Valadares Filho \& Valadares, 2001). O valor médio de eficiência microbiana obtido para as dietas (de 130,08 gPBmic/kg de NDT) foi similar ao valor médio sugerido pelo NRC (2001), de130 g $\mathrm{PBmic} / \mathrm{kg}$ de NDT.

\section{Conclusões}

A substituição do milho pela casca de café ou pela casca de soja nos níveis de $25 \%$ ou $50 \%$, com base na MS da dieta, respectivamente, não promove aumento na atividade mastigatória e na melhora do ambiente ruminal de vacas de leite recebendo dietas com cana-de-açúcar e $60 \%$ de concentrado.

O milho pode ser substituído por casca de café ou casca de soja em níveis de 25 ou 50\%, com base na MS da dieta, respectivamente, sem comprometer a eficiência de utilização dos compostos nitrogenados, a síntese de compostos nitrogenados microbianos ruminais e a eficiência microbiana ruminal de vacas com produção diária de $20 \mathrm{~kg}$ de leite alimentadas com dietas com cana-de-açúcar e $60 \%$ de concentrado.

\section{Literatura Citada}

BARCELOS, A.F.; PAIVA, P.C.A.; PÉREZ, J.R.O. et al. Fatores antinutricionais da casca e da polpa deshidratada de café (Coffea arabica L.) armazenadas em diferentes períodos. Revista Brasileira de Zootecnia, v.30, n.4, p.1325-1331, 2001 . 
BARCELOS, F.A.; SETTE, R.S.; ANDRADE, I.F. et al. Aproveitamento da casca de café na alimentação de vacas em lactação. Lavras: EPAMIG, v.46, n.6, p.1-4, 1995. (Circular Técnica).

BRODERICK, G.A. Use of milk urea as an indicator of nitrogen utilization in lactating dairy cows. Madison: Agriculture Research Service/US Dairy Forage Research Center, 1995. 122p. (Research Summaries).

BRODERICK, G.A.; CLAYTON, M.K. A statistical evaluation of animal and nutritional factors influencing concentrations of milk urea nitrogen. Journal of Dairy Science, v.80, n.11, p.2964-2971, 1997.

BÜRGER, P.J.; PEREIRA, J.C.; QUEIROZ, A.C. et al. Comportamento ingestivo em bezerros holandeses alimentados com dietas contendo diferentes níveis de concentrado. Revista Brasileira de Zootecnia, v.29, n.1, p.236-242, 2000.

BUTLER, W.R.; CHERNEY, D.J.R.; ELROD, C.C. Milk urea nitrogen (MUN) analysis: field trial results on conception rates and dietary inputs. In: CORNELL NUTRITION CONFERENCE FOR FEED MANUfACTURES, 1995, Ithaca. Proceedings... Ithaca: Cornell University, 1995. p.89-95.

CHEN, X.B.; GOMES, M.J. Estimation of microbial protein supply to sheep and cattle based on urinary excretion of purine derivatives - an overview of technical details. Aberdeen: Rowett Research Institute/ International Feed Research Unit, 1992. 21p. (Occasional Publication).

CHIZZOTTI, M.L. Avaliação da casca de algodão para novilhos de origem leiteira e determinação da excreção de creatinina e produção de proteína microbiana em novilhas e vacas leiteiras. Viçosa, MG: Universidade Federal de Viçosa, 2004. 132p. Dissertação (Mestrado em Zootecnia) - Universidade Federal de Viçosa, 2004

COELHO DA SILVA, J.F.; LEÃO, M.I. Fundamentos da nutrição de ruminantes. Piracicaba: Livroceres, 1979. 380p.

COSTA, M.G.; CAMPOS, J.M.S.; VALADARES FILHO, S.C. et al. Desempenho produtivo de vacas leiteiras alimentadas com diferentes proporções de cana-de-açúcar e concentrado ou silagem de milho na dieta. Revista Brasileira de Zootecnia, v.34, n.6, p.2437-2445, 2005 (supl.).

CUNNINGHAM, K.D.; CECAVA, M.J.; JOHNSON, T.R. Nutrient digestion, nitrogen and amino acid flows in lactating cows feed soybean hulls in place of forage or concentrate. Journal of Dairy Science, v.76, p.3523-3535, 1993.

DADO, R.G.; ALLEN, M.S. Intake limitations, feeding behavior, and rumen function of challenged with rumen fill from dietary fiber or inert bulk. Journal of Dairy Science, v.78, p.118133. 1995

ELLIOTT, J.P.; DRACKLEY, G.C.; FAHEY, J.R. et al. Utilization of supplemental fat by dairy cows fed diets varying in content of nonstructural carbohydrates. Journal of Dairy Science, v.78, p.1512-1525, 1995.

FERGUSON, J.D. [2001] Milk urea nitrogen. Disponível em: http://cahpwww.vet.upenn.edu/mun/mun_info.html Acesso em 10/01/05.

FROSI, R.A.M.; MUHLBACH, P.R.F. Nitrogênio uréico no sangue (BUN) e nitrogênio uréico no leite (MUN) como ferramenta para monitorar o status protéico e energético da dieta de ruminantes. In: RIBEIRO, A.M.L; BERNARDI, M.L.; KESSLER, A.M. (Eds.) Tópicos em produção animal 1. Porto Alegre: Universidade Federal do Rio Grande do Sul, 1999. p.41-54.

HALL, M.B. Recent advances in non-carbohydrates for the nutrition of lactating cows. In: SINLEITE - SIMPÓSIO INTERNACIONAL NOVOS CONCEITOS EM NUTRIÇÃO, 2., 2001, Lavras. Anais... Lavras: Universidade Federal de Lavras, 2001. p.139-159.

HARRIS JR., B. Using milk urea nitrogen and blood urea values as management tools. In: LYONS, T.P.; JACQUES, K.A. (Eds.) Biotechnology in the feed industry. Nottingham: Nottingham University Press, 1996. p.75-81.
IPHARREGUERRE, I.R.; CLARK, J.H. Review: soyhulls for dairy cows. Journal of Dairy Science, v.86, n.4, p.1052-1073, 2003 .

JONKER, J.S.; KOHN, R.A.; ERDMAM, R.A. Using milk urea nitrogen to predict nitrogen excretion and utilization efficiency in lactating dairy cows. Journal of Dairy Science, v.81, p.2681-2692, 1998 .

LENG, R.A.; NOLAN, J.V. Nitrogen-metabolism in the rumen. Journal of Dairy Science, v.67, n.5, p.1072-1089, 1984.

LENG, R.A.; PRESTON, T.R. Sugar cane for cattle production; present constraints, perspectives and research priorities. Tropical Animal Production, v.1, n.1, p.1-26, 1976.

LICITRA, G.; HERNANDEZ, T.M.; van SOEST, P.J. Standardization of procedures for nitrogen fractionation of ruminant feeds. Animal Feed Science and Technology, v.57, n.4, p.347-358, 1996.

MACHADO, P.F.; CASSOLI, L.D. In: SINLEITE - SIMPÓSIO INTERNACIONAL DE LEITE, 3., 2002, Lavras. Anais... Lavras: Universidade Federal de Lavras, 2002. p.161-179.

MERTENS, D.R. Physically effective NDF and its use in formulation dairy rations In: SINLEITE - SIMPÓSIO INTERNACIONAL NOVOS CONCEITOS EM NUTRIÇÃO, 2., 2001, Lavras. Anais... Lavras: Federal de Lavras, 2001. p.51-76.

MOORE, D.A.; VARGA, G. BUN and MUN: urea nitrogen testing in dairy cattle. Compendium Continuing Education Veterinary, v.18, n.6, p.712-721, 1996.

MORRISON, M.; MACKIE, R.I. Nitrogen metabolism by ruminal microorganisms: current understanding and future perspectives. Australian Journal Agriculture Research, v.47, n.2, p.227246, 1996.

NATIONAL RESEARCH COUNCIL - NRC. Nutrient requirements of dairy cattle. 7.ed. Washington, D.C.: National Academy Press, 2001. 381p.

NOUSIAINEN, J.; SHINGFIELD, K.J.; HUHTANEN, P. Evaluation of milk urea nitrogen as a diagnostic of protein feeding. Journal of Dairy Science, v.87, p.386-398, 2004

OLIVEIRA, A.S.; CAMPOS, J.M.S; VALADARES FILHO, S.C. et al. Consumo, digestibilidade aparente dos nutrientes, produção e composição do leite vacas leiteiras alimentadas com dietas à base de cana-de-açúcar contendo casca de café ou casca de soja. Revista Brasileira de Zootecnia, 2007 (no prelo).

OLIVEIRA, A.S.; VALADARES, R.F.F.; VALADARES FILHO, S.C. et al. Produção de proteína microbiana e estimativas das excreções de derivados de purinas e de uréia em vacas lactantes alimentadas com rações isoprotéicas contendo diferentes níveis de compostos nitrogenados não-protéicos. Revista Brasileira de Zootecnia, v.30, n.5, p.1621-1629, 2001

OLIVEIRA, M.D.S. Cana-de-açúcar na alimentação de bovinos. Jaboticabal: Universidade Estadual Paulista, 1999. 128p.

ORTOLONI, E.L. Considerações técnicas sobre o uso da sonda esofágica na colheita do suco de rúmen de bovinos para mensuração do $\mathrm{pH}$. Arquivo da Escola de Veterinária da UFMG, v.33, n.2, p.269-275, 1981

ORSKOV, E.R. Protein nutrition in ruminants. 2.ed. London: Academic Press, 1992. 175p.

RENNÓ, L.N.; VALADARES, R.F.D.; VALADARES FILHO, S.C. et al. Estimativa da produção de proteína microbiana pelos derivados de purinas na urina em novilhos. Revista Brasileira de Zootecnia, v. 24, n.4, p.1223-1234, 2000.

ROCHA, F.C.; GARCIA, R.; FREITAS, A.W.P. et al. Casca de café em dietas de vacas em lactação: consumo, produção de leite e variação de peso. In: REUNIÃO ANUAL DA SOCIEDADE BRASILEIRA DE ZOOTECNIA, 41., 2004, Campo Grande. Anais... Campo Grande: Sociedade Brasileira de Zootecnia, 2004. (CD-ROM).

RUSSELL, J.B.; O'CONNOR, J.D.; FOX, D.J. et al. A net carbohydrate and protein system for evaluating cattle diets: I. Ruminal fermentation. Journal of Animal Science, v.70, n.11, p.3551-3561, 1992. 
SATTER, L.D.; SLYTER, L.L. Effect of ammonia concentration on rumen microbial production in vitro. British Journal Nutrition, v.32, p.199-208, 1974.

SILVA, D.J.; QUEIROZ, A.C. Análise de alimentos: métodos químicos e biológicos. 3.ed. Viçosa, MG: Editora UFV, 2002. $235 \mathrm{p}$.

SOUZA, D.P. Desempenho, síntese de proteína microbiana e comportamento ingestivo de vacas leiteiras alimentadas com caroço de algodão em substituição à cana-de-açúcar corrigida. Viçosa, MG: Universidade Federal de Viçosa, 2003. 79p. Dissertação (Mestrado em Zootecnia) - Universidade Federal de Viçosa, 2003.

SOUZA, A.L.; GARCIA, R.; VALADARES FILHO, S.C. et al. Casca de café em dietas de vacas em lactação: consumo, digestibilidade e produção de leite. Revista Brasileira de Zootecnia, v.34, n.6, p.2496-2504, 2005.

UNIVERSIDADE FEDERAL DE VIÇOSA - UFV. SAEG - Sistema de análises estatísticas e genéticas (Manual do usuário). Versão 7.1. Viçosa, MG: Fundação Arthur Bernardes, 1997. 150p.
VALADARES FILHO, S.C.; ROCHA JR., V.R.; CAPPELLE, E.R Tabelas brasileiras de composição de alimentos para bovinos. Viçosa, MG: Universidade Federal de Viçosa, 2002. $297 \mathrm{p}$.

VALADARES FILHO, S.C.; VALADARES, R.D.F. Recentes avanços em proteína na nutrição de vacas leiteiras. In: SINLEITE SIMPÓSIO INTERNACIONAL: NOVOS CONCEITOS EM NUTRIÇÃO, 2., 2001, Lavras. Anais... Lavras: Universidade Federal de Lavras, 2001. p.229-247.

Van SOEST, P.J. Nutritional ecology of the ruminants. 2.ed. Ithaca: Cornell University, 1994. 476p.

VERBIC, J.; CHEN, X.B.; MACLEOD, N.A. et al. Excretion of purine derivatives by ruminants. Effect of microbial nucleic acid infusion on purine derivative excretion by steers. Journal Agriculture Science, v.114, n.3, p.243-248, 1990.

Recebido: 20/09/05 Aprovado: 28/08/06 